\title{
Evaluation of Herbal Extract of Gentiana diffusa for Antianxiety Activity
}

\author{
Sudipta Dakua*, Rakesh Gawaly, Pratyush Jain, Alok Pal Jain \\ RKDF College of Pharmacy, Bhopal (M.P.) India \\ Sarvepalli Radhakrishnan University Bhopal (M.P.) India
}

\begin{abstract}
Article Info: Received 10 July 2021; Accepted 09 September 2021
DOI: https://doi.org/10.32553/jbpr.v10i5.877

Corresponding author: Sudipta Dakua

Conflict of interest statement: No conflict of interest
\end{abstract}

\begin{abstract}
The present study was designed to authenticate the anti-anxiety activity (by using elevated plus maze model) of methanolic extract of the leaves of Gentiana diffusa. by authors Swiss Albino mice were treated with different doses of the leaf extracts $(200 \mathrm{mg} / \mathrm{kg}$ p.o.) and Diazepam (2mg/ kg, p.o) was used as a positive control. Results of study show that methanolic extract in higher doses $(200 \mathrm{mg} / \mathrm{kg})$ possesses marked anti-anxiety activity and was comparable to the effect produced by diazepam. The plant can be developed as a commercial source of anxiolytic agent. Further studies are in process to isolate the active constituent responsible for this activity and mechanism of action.
\end{abstract}

Keywords: Leaves, Methanol, Anxiety, Diazepam

\section{Introduction}

Herbal medicines are prevalent as remedies for diseases and play a key role in the human healthcare of a massive common of world's population. World's populations rely on the use of traditional medicine, which is predominantly based on plant material. [1] The traditional medicine refers to a broad range of ancient natural health care practices and these medicinal practices have originated from time immemorial and developed gradually, to a large extent, by relying or based on practical experiences, without significant references to modern scientific principles. Although, herbal medicines are effective in the treatment of various ailments, very often these drugs are unscientifically exploited or improperly used. Therefore, these plant drugs justify detailed studies in the light of modern science. [2] Plant and plant products have been used for treating various illnesses. Today, several medicinal plants and their products are still being employed as house remedies, over the counter drugs as well as raw materials for the pharmaceutical industry and they represent a substantial proportion of the global drug market.

Anxiety is a merged progressive behavioral and physiological adjustment of the organism, which ultimately leads to wide variety of central nervous system (CNS) disorders, if remain untreated. In addition to individual genetic factors external influences, such as nutrition, smoking, alcohol, socioeconomic status, environmental conditions etc., can strongly contribute to its predicted arrival. [3] In Indian system of medicinal plants, many plants have been prescribed for the treatment of CNS 
disorder. Gentiana diffusa is one such plant reported for the treatment of CNS disorders. Literature survey revealed that plants having flavonoids and terpenoids, alkaloids and tannins showed potent activity for the treatment and prevention of stress and anxiety. Thus, it was hypothesized that Gentiana diffusa should also showed proposed activity.

\section{Experimental work}

\section{Collection \& Identification of Plant material}

The crude drug of Gentiana diffusa was collected from available sources. The plant part (leaves) will be shade-dried, powdered to 40 mesh particle size and stored in air tight container. Plant specimens were identified and authenticated. The powder drug of whole plant was dried in shade \& used for extraction.

\section{Extraction of plant drug}

The powdered plant material (about 90 gm) was extracted with methanol (95\%) in a soxhlet apparatus. The solvent was removed under reduced pressure, which obtained a dark brown sticky residue with respect to dried plant material. The dried extract was stored in a desicator till further study. The percentage yield of methanolic extract was calculated as $5.0 \%$ w/w.

\section{In vivo study for the assessment of anti- anxiety activity of plant drug}

\section{Animals}

Albino rats of approximately 8-10 weeks of age weighing 40 to $60 \mathrm{~g}$ were taken. The institutional animal ethical committee permitted the study. The animals were housed in standard cages, at room temperature $\left(25 \pm 3^{\circ} \mathrm{C}\right)$, with $12 \mathrm{hr}$ light cycles, all the animals were fed with standard pellet diet. They were given 2 weeks' time to get acclimatized with laboratory conditions.

\section{Grouping of animals}

Group I: Received Vehicle (Control)
Group II: Standard group received Diazepam $(2 \mathrm{mg} / \mathrm{kg})$

Group III: Test group received methanolic extract of Gentiana diffusa (200 mg/kg)

\section{Elevated plus maze (EPM) model of anxiety}

The plus-maze apparatus consisting of two open arms $(16 \times 5 \mathrm{~cm})$ and two closed arms $(16 \times 5 \times$ $12 \mathrm{~cm}$ ) having an open roof, with the plus-maze elevated $(25 \mathrm{~cm})$ from the floor was used to observe anxiolytic behaviour in animals. Each mouse was placed at the centre of the elevated plus maze with its head facing the open arms. During this 5 minutes experiment, the behavior of the mouse was recorded as: (a) the number of entries into the open arms, (b) average time spent by the mouse in the open arms (average time $=$ total time spent in open arms/number of entries in arms). Extract of Gentiana diffusa was administered orally using a tuberculin syringe fitted with oral canula. The dose administration schedule was so adjusted that each mouse was having its turn on the elevated plus-maze apparatus 45 minutes after the administration of the dose. During the entire experiment, the animals were allowed to socialize. $[4,5,6]$

\section{Statistical Analysis}

Experimental data are expressed as mean \pm standard error of mean (SEM). Statistical analysis was performed using Dunnet vs. control test followed by one-way ANOVA to identify the differences between pair of groups. Data were considered significant at $p<0.01$.

\section{Results and Discussion}

\section{In vivo study for the assessment of anti- anxiety activity of plant drug}

For the assessment of anti-anxiety activity of Gentiana diffusa, Number of entries in open arms and Average time spent in open arms were assessed. The results were recorded and calculated. 
Table 1 Evaluation of anti-anxiety activity of plant drug

\begin{tabular}{|l|l|l|l|}
\hline Treatments & Dose & $\begin{array}{l}\text { Number of entries in open } \\
\text { Arms Mean } \pm \text { S. }\end{array}$ & $\begin{array}{l}\text { Average time spent in } \\
\text { open arms Mean } \pm \text { S. }\end{array}$ \\
\hline Control & Vehicle & $2.15 \pm 0.15^{*}$ & $2.30 \pm 0.40^{* *}$ \\
\hline Standard & Diazepam $(2 \mathrm{mg} / \mathrm{kg})$ & $5.10 \pm 0.28^{* *}$ & $10.70 \pm 0.54^{* *}$ \\
\hline Methanol extract & $(400 \mathrm{mg} / \mathrm{kg})$ & $4.50 \pm 0.20^{*}$ & $7.30 \pm 0.18^{* *}$ \\
\hline
\end{tabular}

The data is expressed as Mean \pm S.D.; ${ }^{*} \mathrm{P}<0.05, * * \mathrm{P}<0.01$

\section{Conclusion}

The conclusion of the present study suggest that it can serve as a valuable source of information and provide appropriate standards to ascertain the quality of this plant material in future study or application, moreover it could be a possible source therapeutic agents in preventing or slowing the development of blood and related compounds. The flavonoids of the plant appear most likely as the active ingredients responsible for the antianxiety effect of plant.

\section{Acknowledgment}

The authors are thankful to the management of Sarvepalli Radhakrishnan University, Bhopal (M.P.) for providing all the necessary facilities for the completion of this work.

\section{References}

1. Thakur Priyanka, Rana AC. Anxiolytic potential of medicinal plants. International Journal of Nutrition, Pharmacology, Neurological Diseases. 2013; 3(4): 325331.
2. Sandhya S, Vinod KR, Kumar S (2010). Herbs used for brain disorders. Hygeia J D Med. 2: 38- 45.

3. LeDoux J. Fear and the brain: Where have we been, and where are we going? Biol Psychiatry 1998;44:1229-38.

4. Abidemi J. Akindele, Hakeem A. Sanni, and Pamela C. Edeh. Anxiolytic activity of aerial part hydroethanolic extract of Allium ascalonicum Linn. (Liliaceae) in mice. Functional Foods in Health and Disease. 2012, 2(11):448-459.

5. Yadav AV, Kawale LA, Nade VS. Effect of Morus alba L. (Mulberry) leaves on anxiety in mice. Indian Journal of Pharmacology. 2008;40: 32-36.

6. Gupta V, Bansal P, Kumar P, Shri R (2010). Anxiolytic and antidepressant activities of different extracts from Citrus paradisi var. duncan. Asian Journal of Pharmaceutical and Clinical Research 3: 98-100. 